\title{
Size of Persistent and Solid Component of a Sub-Solid Pulmonary Nodule
}

National Cancer Institute

\section{Source}

National Cancer Institute. Size of Persistent and Solid Component of a Sub-Solid

Pulmonary Nodule. NCI Thesaurus. Code C138078.

The size of the solid component of a solitary part-solid nodules, as observed through CT imaging. 